\title{
ASSESSING THE ROLE OF SPATIAL RAINFALL VARIABILITY ON WATERSHED RESPONSE BASED ON WEATHER RADAR DATA (A CASE STUDY OF THE GARD REGION, FRANCE)
}

\author{
Evi Anggraheni ${ }^{*}$, Dwita Sutjiningsih ${ }^{1}$, Isabelle Emmanuel ${ }^{2}$, Olivier Payrastre $^{2}$, Herve Andrieu $^{2}$ \\ ${ }^{1}$ Department of Civil Engineering, Faculty of Engineering, Universitas Indonesia, Kampus UI \\ Depok,Depok 16424, Indonesia \\ ${ }^{2}$ PRES L'UNAM, IFSTTAR, Département GERS, and IRSTV, FR CNRS 248, Bouguenais, France
}

(Received: July 2017 / Revised: January 2018 / Accepted: February 2018)

\begin{abstract}
Rainfall is the primary input into rainfall-runoff modeling. Previous work indicates that the accurate representation of rainfall in time and space is important due to its influence on the hydrological response. The objective of this study is to evaluate the relevance of theoretical indices of spatial rainfall variability and the theoretical criteria of the hydrological response proposed by Emmanuel et al. (2015) in a real case study. The distributed model CINECAR has been chosen to accommodate the spatial discretization of hydrological data. The production function of the model adopts the Soil Conservation Service-Curve Number method, while the transfer function is based on a kinematic wave model. The simulations used weather radar data and also their average over the watershed, with a data resolution of $1 \times 1 \mathrm{~km}^{2}$. They were conducted on the basis of 13 watersheds in the Gard region and four events in 2008 for each watershed. The difference between the distributed and averaged hydrographs obtained from the CINECAR model were calculated using two criteria, namely the difference in peak discharge (LQ) and the difference in peak time (TQ). The values of LQ and TQ represent the influence of spatial rainfall variability on the hydrological response. The spatially distributed rainfall was analyzed based on the values of its maximum Horizontal and Vertical Gab (HG and VG) to watershed centroid acting as indices, as proposed by Emmanuel. The analysis of the influence of spatial rainfall variability on the watershed response was conducted by quantification of the averaged and distributed hydrographs using the proposed indices and criteria. The results show that value of LQ rises by more than $50 \%$ for some events, and that TQ shows different times to peak between the average and distributed hydrographs. The values of the HG and VG indices accurately describe the rainfall distribution in the watershed. Therefore, these criteria and indices are effective in quantifying the influence of spatial rainfall variability on the hydrological modeling in particular events which are affected by rainfall distribution.
\end{abstract}

Keywords: Hydrological modelling; Indices of spatial rainfall Variability; SCS-CN; Spatial rainfall variability; Surface runoff

\section{INTRODUCTION}

The main input for hydrological and environmental model is rainfall. The accurate representation of rainfall in time and space is important for rainfall-runoff modelling due to its impact on hydrological responses. The impact of spatial rainfall variability on hydrological

\footnotetext{
*Corresponding author's email: evi.anggraheni@yahoo.com, Tel: +62-21-7270029, Fax: +62-21-7270028 Permalink/DOI: https://doi.org/10.14716/ijtech.v9i3.498
} 
response representation depends on the type of rainfall, the catchment characteristics (nature and scale), and rainfall distribution. Many researchers have been observing the influence of spatial rainfall variability for the last 40 years, but there are still contradictive results. Kriging and multi quadratic surface fitting can be used in order to acquire a quantitative evaluation and spatial distribution of precipitation in hydrology and water resource management (Borga \& Vizzaccaro, 1997). The results of their research show that kriging operates better at a lower gauge density. When tested on higher gauge density, the estimator values proved to be similar. The representation of rainfall on the hydrological model plays an essential part in terms of performance of the surface hydrology and runoff production (Wheater et al., 2000).

In order to obtain accurate rainfall data in time and space, the study of weather radar images has been developed to procure detailed knowledge of rainfall spatial variability, which is not available with rain gauge networks. The high-resolution radar estimations, both in time and space, are needed to properly simulate flash flood (Anquetin et al., 2010). In another study, the benefit of weather radar data featuring high temporal and spatial resolution of rainfall is confirmed (Emmanuel et al., 2012). In 2013, a study was proposed contributing to the stochastic approach, with the particularity of the adaption of a classical Gaussian random field generator, the Turning Band Method (TBM), to simulate advected intermittent rainfall fields to represent rainfall in space and time (Leblois \& Creutin, 2013).

In line with all previous studies, analysis of the influence of spatial rainfall variability on the watershed response is still a debatable issue. For example, Wood et al. (1988) noticed that the increment in the contributing area will weaken the influence of spatial rainfall variability and the scale of the hydrological response. Zoccatelli et al. (2010), who studied three extreme flash flood events on catchments of $36 \mathrm{~km}^{2}$ to $167 \mathrm{~km}^{2}$ in Romania, reported that neglecting spatial rainfall variability results in the loss of a considerable amount of modelling efficiency, in about $30 \%$ of the cases. In the same year, Anquetin et al. (2010) suggested that rainfall remains the most influential factor in hydrological responses. Zhao et al. (2013) state that spatial rainfall variability is important for hydrological model performance, neglecting the fact that it will increase errors and decrease model accuracy. The spatial and temporal characteristics of rainfall have demonstrated a significant influence on watershed response predictions (Caracciolo et al., 2014).

On the contrary, another studies have explained that in the mean catchment, a single event with long rainfall duration has less influence (Tetzlaff \& Uhlenbrook, 2005). The conclusion about rainfall pattern size and distribution insignificantly influence the hydrological response (Nicotina et al., 2008). Based on their research, the significant parameter which does influence this response is total travel time within the hill slope. Adam et al. (2012) noticed that averaging the rainfall routing will remove the majority of effects on the impact of rainfall spatial variability in the catchment area $\left(150 \mathrm{~km}^{2}\right)$. Recently, Emmanuel et al. (2015) have proposed two indices and criteria which can suggest the influence of spatial rainfall variability on the watershed response. They conclude that the indices and criteria may better explain the impact of spatial rainfall variability on the catchment response. The simulation chain proposed in their study includes a stream network model, rainfall simulator and a distributed hydrological model.

Based on previous research, the objective of this study is to evaluate the relevance of theoretical indices of spatial rainfall variability and the theoretical criteria of the hydrological response proposed by Emmanuel et al. (2015) in the real case study.

\section{METHODOLOGY}

\subsection{Case Study Identification}

The Gard region is an administrative territory located in South East France. It has a typical Mediterranean climate, characterized by frequent and very heavy storm events, especially in 
autumn (Versini et al., 2010a). The region is divided into six watersheds (Figure 1): Gardon (2200 $\mathrm{km}^{2}$ ), Ceze $\left(1359 \mathrm{~km}^{2}\right)$, Vidourle $\left(1335 \mathrm{~km}^{2}\right)$, Hérault $\left(2500 \mathrm{~km}^{2}\right)$, Dourbie $\left(548 \mathrm{~km}^{2}\right)$ and Vistre $\left(220 \mathrm{~km}^{2}\right)$. In this case study, we only consider the three main watersheds, which are Gardon, Ceze and Vidourle.

The region is also frequently affected by flash floods (Gaume et al., 2009). In 2002, the extreme intensity, with a maximum accumulated precipitation of about $610 \mathrm{~mm}$, was recorded in 24 hours. The event led to the loss of 23 human lives and caused 1.2 billion euros of damage in less than 24 hours, over an area of $20.000 \mathrm{~km}^{2}$ (Delrieu, 2005).

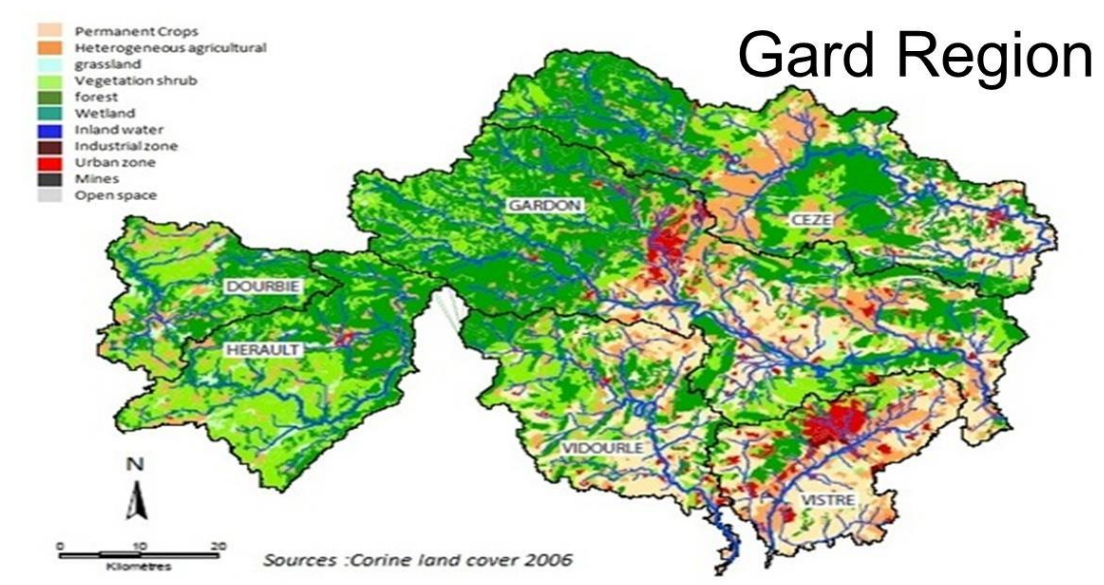

Figure 1 Watershed and principal land use of the Gard region

\subsection{Explanation of the Simulation Process}

The proposed simulation process for the study started by calculating the rainfall data with an $\mathrm{R}$ program from the weather radar data and by averaging the spatial rainfall data. A distributed hydrograph from the CINECAR model was chosen to accommodate the watershed characteristics. The influence of spatial rainfall variability was analyzed from the hydrograph criteria. The rainfall organization that affected the hydrological response is explained by the proposed indices, and evaluation of the relevance of the theoretical indices and criteria in the case study will be the last step. Figure 2 shows the simulation process of the study.

\subsubsection{Rainfall input data}

The impact of rainfall spatial variability was studied by considering two different rainfall inputs. The first was obtained from the $\mathrm{C}$ band weather radar located in Nimes and Bolene, with a spatial resolution of $1 \mathrm{~km} \times 1 \mathrm{~km}$. This also has a temporal resolution of 5 minutes, which is called distributed rainfall. The second input is the average of the distributed rainfall over the catchment area at each time by averaging the distributed rainfall of each sub-watershed pixel. Hence, each sub-watershed pixel collects the same amount of raw rainfall at each time step, which is called average rainfall.

\subsubsection{CINECAR hydrological model}

The CINECAR model was constructed precisely to model flash floods. In addition, it has been used to simulate the extreme floods that occurred in 2002 and which caused loss of life due to road inundation in the Gard region of Southern France (Delrieu, 2005). The initial prototype of the model was used to map possible road inundations in this region (Versini et al., 2010a). The production function of the CINECAR model adopted the Soil Conservation Service - Curve Number (SCS-CN) model. This was chosen as it illustrates the hydrological process in the watershed; its production function depends on the $\mathrm{CN}$ value, the soil characteristic and the 5 dayantecedent rainfall. 


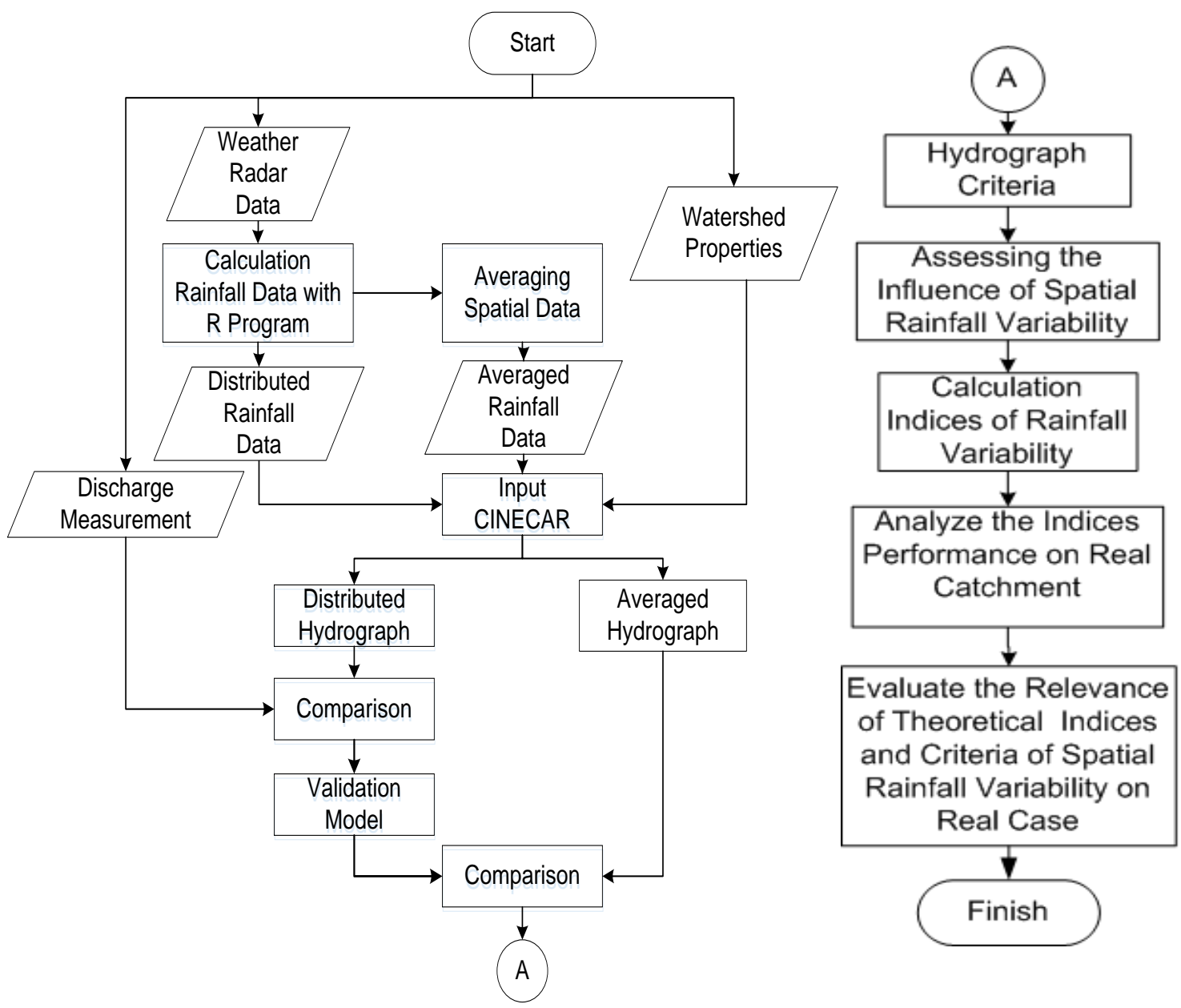

Figure 2 Simulation Process

The CINECAR model is distributed hydrological modeling and is based on the representation of the watershed area as a ramified series of stream reaches with a rectangular cross-section, with which left and right hand hill slopes are associated. The reaches define the flow paths through the watershed area to its outlet. The routine in each reach of the CINECAR model uses the Kinematic Wave equation for continuity and momentum as the governing equation for one-dimensional, unsteady flow in an open channel.

\subsection{Criteria and Indices Used to Evaluate the Impact of Rainfall Spatial Variability}

2.3.1. Criteria used to evaluate the impact of rainfall spatial variability on the watershed response

The objective of this step is to evaluate the influence of rainfall spatial variability. For this, the two different rainfall inputs considered were distributed rainfall and average rainfall. The pairs of hydrographs obtained (called the "distributed hydrograph" and "averaged hydrograph") were compared for the $13 \mathrm{sub}$-watersheds and the four selected events in 2008. The distributed hydrographs obtained from the weather radar data were set as the reference. The differences between each pair of hydrographs provide an impact indication of the rainfall spatial variability on the watershed response. Two criteria are proposed: difference in peak discharge, denoted by LQ, and difference in time discharge, denoted by TQ. 


$$
\begin{array}{r}
L_{Q}=\frac{Q_{\text {maxDist }}-Q_{\text {avg }}}{Q_{\text {maxDist }}} \boldsymbol{x} 100 \\
\mathrm{~T}_{\mathrm{Q}}=\mathrm{T}_{\text {peakDist }}-\mathrm{T}_{\text {peakAvg }}
\end{array}
$$

\subsubsection{Indices of rainfall spatial variability}

The function of these indices is to identify situations in which rainfall spatial variability may have an influence on the watershed response and to make precise the relevance of the distributed hydrological modeling in the function of watersheds and rainfall characteristics. The computation of these indices relies on detailed analysis of rainfall spatial organization in the function of flow distances (the distance measured along the stream network from one point of the watershed to the outlet) and this computation is made using the raw rainfall distributed radar data.

a) Rainfall Position Index

Zoccatelli et al. (2010) proposed the index $\left(\theta_{1}\right)$, which determines the rainfall position based on the catchment centroid:

$$
\theta_{1}=\frac{\text { Rainfall Centroid }}{\text { Catchment Centroid }}
$$

As explained by Zoccatelli et al.; $\theta_{1}$ describes the distance of the centroid of the watershed rainfall with respect to the watershed centroid. Values of $\theta_{1}$ close to 1 reflect a rainfall distribution either concentrated close to the position of the watershed centroid or which are spatially homogenous. Values less than 1 (or greater than 1) indicate that rainfall is distributed downstream (or upstream).

b) Spatial Rainfall Variability Index

The other two indices proposed by Emmanuel et al. (2015) are VG (Vertical Gab) and HG (Horizontal Gab). Their computation is based on the distribution of rainfall accumulations in the function of flow distances.

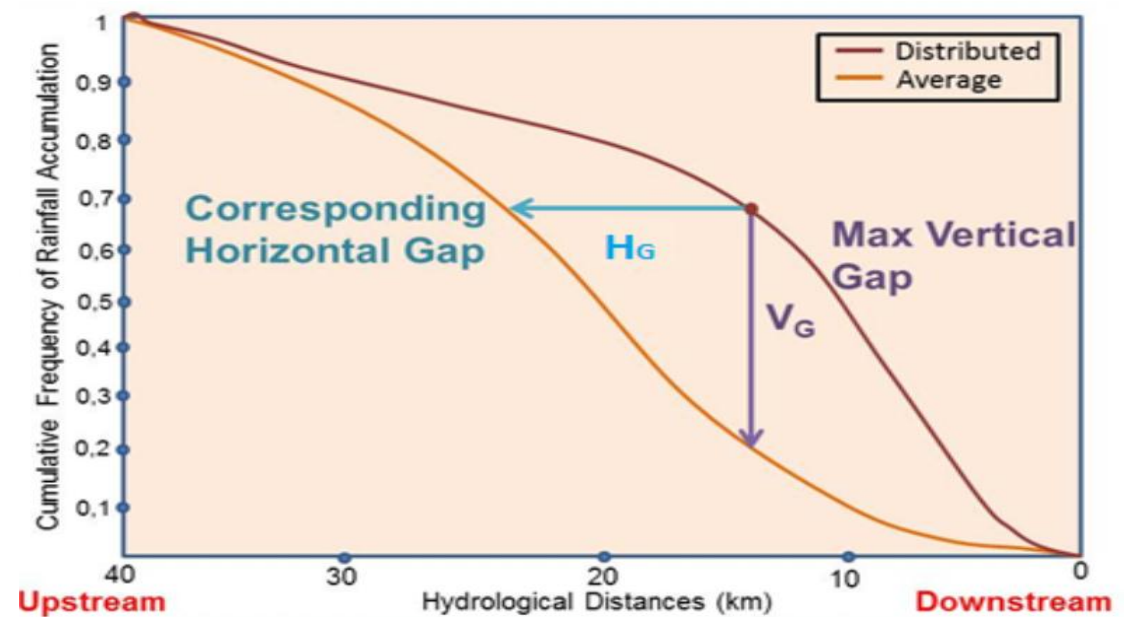

Figure 3 Principle of computation of the rainfall variability indices VG and HG

Two distributions are obtained by using, respectively, the distributed rainfall accumulation and the average rainfall accumulation over the watershed. The value of VG is obtained from the maximum absolute value of the vertical difference between the two functions (distributed and averaged). HG is the corresponding difference between both width functions divided by the length of the longest hydrological path of the catchment, as the absolute value of the maximum vertical difference between the two width functions. All their computation was analysed using 
rainfall simulator data and stream network modelling.

\section{RESULTS}

\subsection{Hydrological Model Performance}

The aim of this step was to confirm the performance of the CINECAR hydrological model in the study. For this simulation, a comparison of the distributed rainfall using the model, called model hydrographs, and the measured hydrographs at the outlet of the 13 sub-watersheds, was made for the 12 events which occurred in 2008. An example of the comparison between the obtained hydrographs is shown in Figure 4.

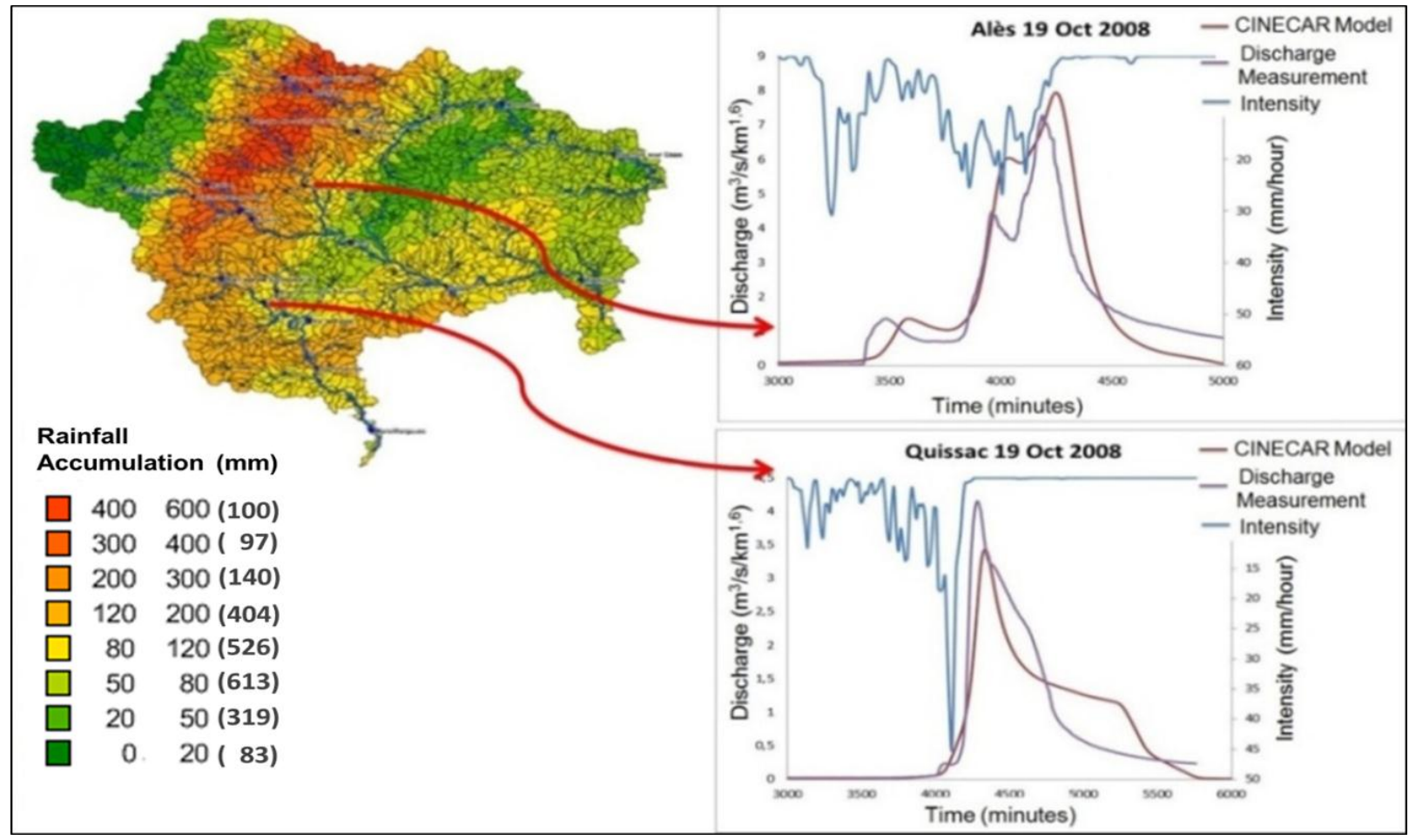

Figure 4 Comparison of the modeled and the measured hydrographs for the 19 October 2008 event located at the Ales and Quissac stations

In this simulation, we selected four events that produced high outflows (more than $0.5 \mathrm{~m}^{3} / \mathrm{s} / \mathrm{km}^{1.6}$ ) and the calibration of the CINECAR model led to accurate hydrological model results. This observation is consistent with previous results from (Naulin et al., 2013), which shows that the model had a good performance for intense rainfall events, independently from the level of rainfall spatial variability.

\subsection{Spatial Rainfall Variability Indices Performance}

The objectives of these indices were to identify situations in which rainfall spatial variability may have an influence on the watershed response and to make precise the relevance of the distributed hydrological modeling in the function of watersheds and rainfall characteristics on the real watershed. In this study, these indices were tested with the real watershed and their relevance checked against the rainfall criteria (LQ and TQ). The value of VG corresponds to the absolute value of the maximum vertical gap between these two distributions (distributed and average). The HG value is equal to the horizontal corresponding gap, divided by the length of the longest hydrological path of the watershed. From some simulations, we obtained the relevance of these indices and criteria. We suggest that the value of VG indicates the difference in the peak discharge 
(ED). The values of $\Theta_{1}$ and $H G$ indicate the difference in peak time. Figures $5 \mathrm{a}$ and $5 \mathrm{~b}$ show an example of obtained results.
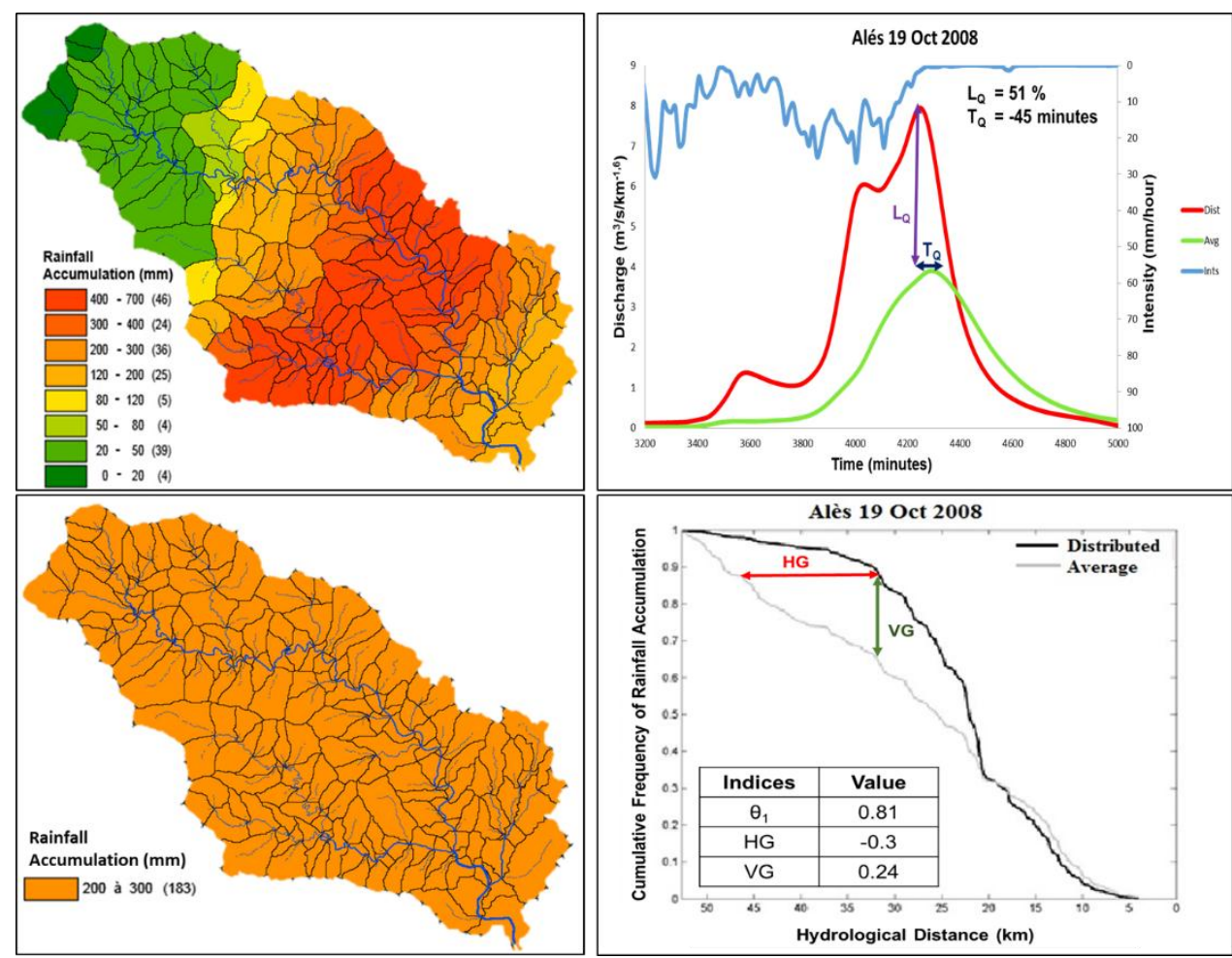

Figure 5a Calculation of indices from the 19 October 2008 event at Ales

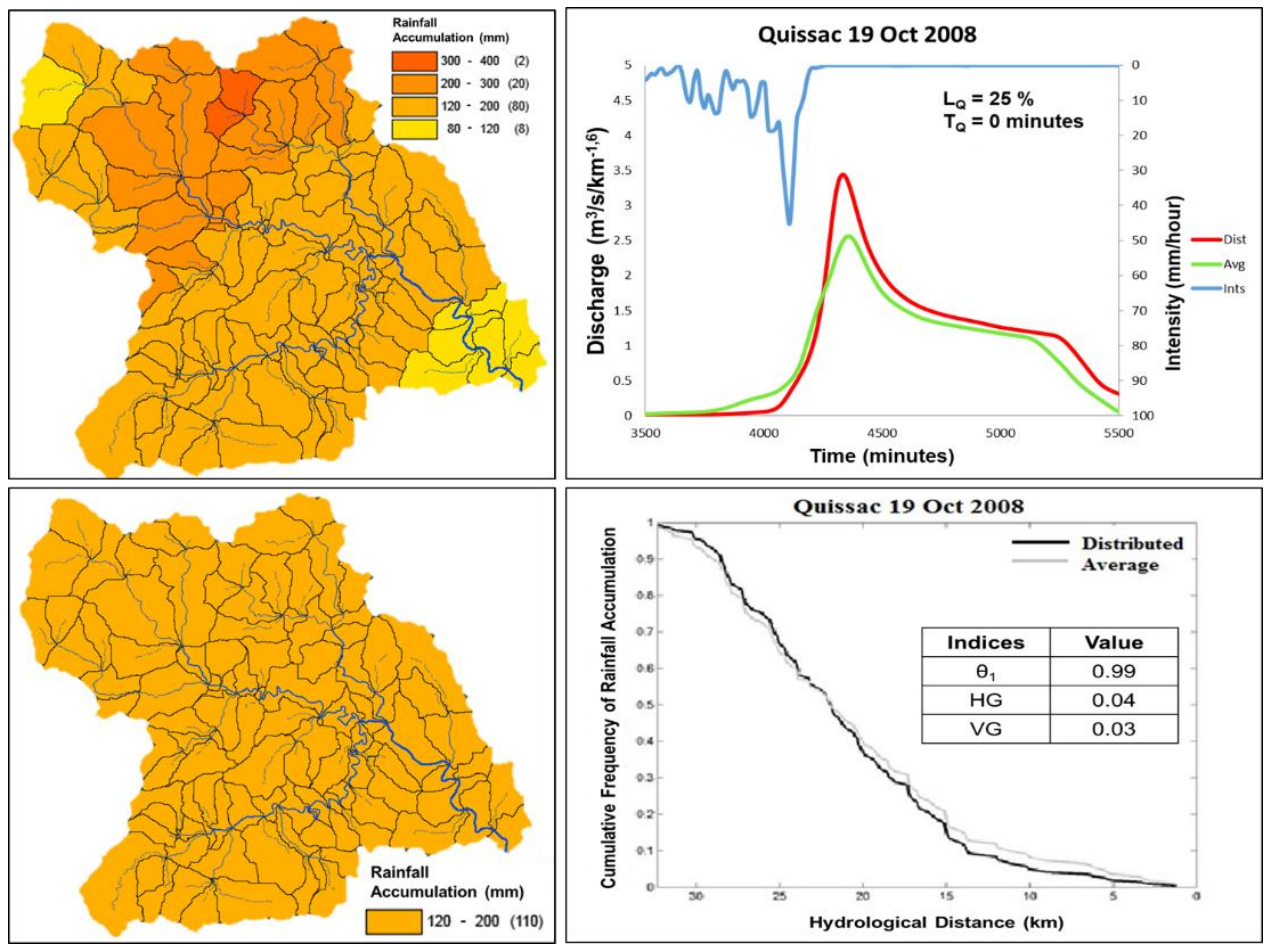

Figure 5b Calculation of indices from the 19 October 2008 event at Quissac

The results indicate that the influence of rainfall spatial variability depends highly on the rainfall event considered and on the level of organization of the rainfall. According to Figure 5a, when the rainfall seems heterogeneous over the catchment area, the differences in peak discharges can 
reach up to $50 \%$ coherence with the value of $\mathrm{VG}$, and the difference in peak time is 45 -minute coherence with the values of $\theta_{1}$ and HG. In this condition, the values of both the criteria and the indices are coherent. However, if the rainfall is homogenous over the studied watershed (Figure $5 b$ ), both hydrographs are similar. The peak of the distributed hydrograph arrived at the same time as the peak of the averaged hydrograph, shown with the value of TQ in 0 minute coherence with the values of $\theta_{1}$ and HG. The difference between the two peak discharges is represented by the value of LQ, which is approximately $25 \%$ not coherent with the value of $\mathrm{VG}$, which is close to 0 .

\section{DISCUSSION}

According to the model, the behavior of the studied watersheds may sometimes remain similar to a homogeneous rainfall input, whereas in some cases the differences in the peak discharges can reach up to 50\%. The criteria and indices are effective in quantifying the effect of neglecting the rainfall spatial variability on the hydrological modeling. The results of the rainfall organization indices $\left(\theta_{1}\right.$ and $\left.\mathrm{HG}\right)$ are coherent with the peak time criteria (LT). However, the discharge magnitude index $(\mathrm{VG})$ and the peak discharge criterion $\left(\mathrm{L}_{\mathrm{Q}}\right)$ are in some cases not coherent. Based on the theoretical meaning of the indices and criteria, the value of VG should be coherent with the value of $\mathrm{L}_{\mathrm{Q}}$. If the value of $\mathrm{VG}$ is approximately 0 , the value of $\mathrm{L}_{\mathrm{Q}}$ is also close to 0 . For the distributed rainfall, the values of $\mathrm{VG}$ and $\mathrm{L}_{\mathrm{Q}}$ are coherent. However, for the homogeneous rainfall distribution (average and distributed rainfall seem to be similar), $\mathrm{VG} \approx 0$, but $\mathrm{L}_{\mathrm{Q}}$ still has an important value. Figure $5 \mathrm{a}$ shows the coherence between the criteria and indices, while Figure $5 \mathrm{~b}$ shows an error in $\mathrm{VG}$ and $\mathrm{L}_{\mathrm{Q}}$.

The rainfall organization in Figure 6 represents the homogeneous rainfall over the watershed that caused the error in the indices and criteria.

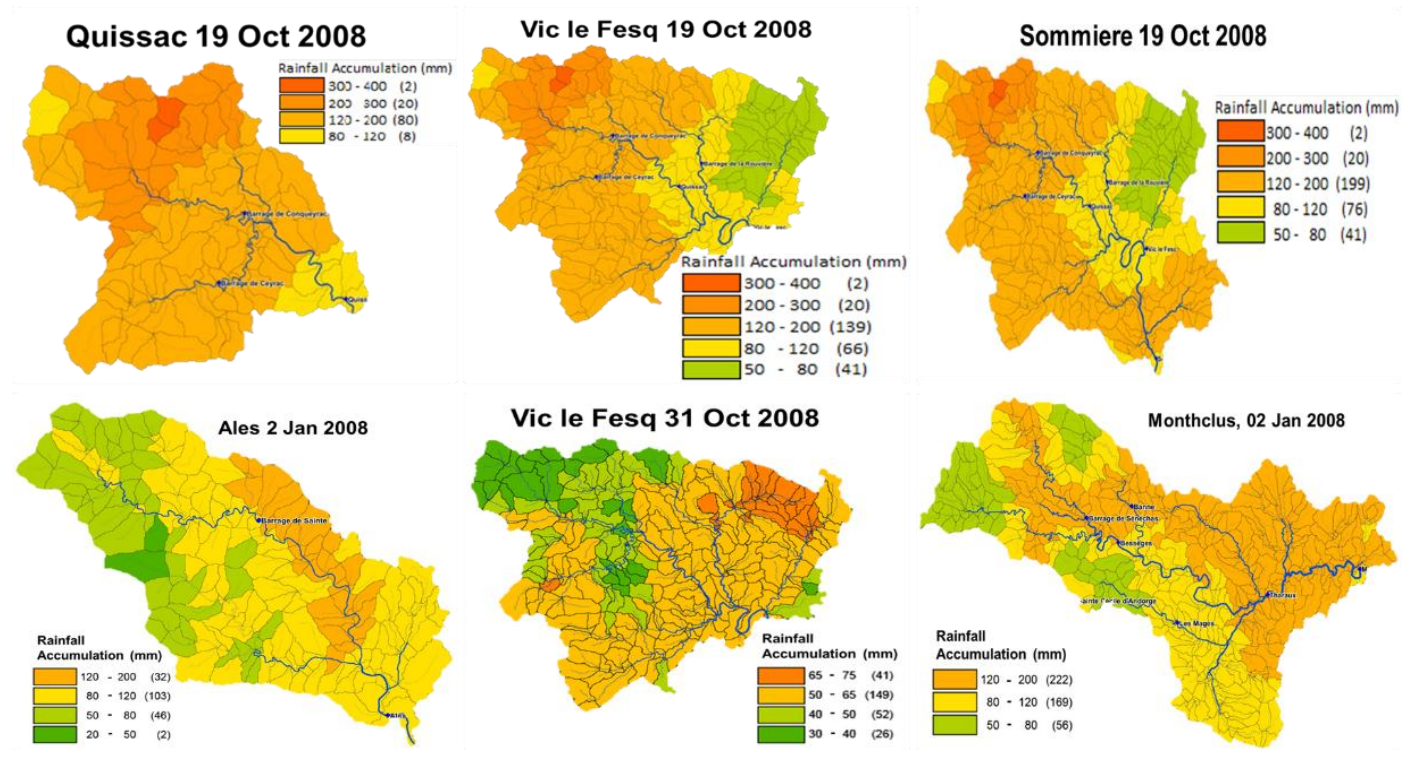

Figure 6 Homogenous rainfall distribution

The computation of the indices does not take account on the watershed parameter. However, the computation of the criteria is based on the different peaks of the hydrographs that consider the watershed parameters. This condition indicates that there is other parameter variability which plays a role in hydrological response. This result corresponds to that of (Anquetin et al., 2010), who suggest that soil characteristics are an important source of uncertainty in the understanding of the hydrological behaviour of the catchments. In other research, (Rodriguez et al., 2008) 
confirm that urban soil and soil-atmosphere interaction is important in hydrological processes. The inclusion of factors characteristic of the interaction between spatial rainfall distribution with other spatial distribution, such as soil properties, would seem to be appropriate in making a better assessment of the amplification or attenuation of the hydrological response (Douinot et al., 2016). Based on the comparison between the criteria and indices, we suggest analysis is made of other variables which may influence the watershed response.

\section{CONCLUSION}

The proposed indices of Emmanuel et al. (2015) show relevant results to the theoretical indices of spatial rainfall variability on the hydrological response in the specific context of flash floods on the real watershed. However, for several homogenous rainfall events, the indices have no relevance to the hydrograph criteria. The different results between the indices and criteria indicate that the hydrological response (discharge) is affected not only by rainfall variability, but also by the variability of the other parameters. The computation of the indices has been made by the distribution of rainfall accumulations in the function of flow distances. This approach should be the validation of the proposed analysis above, which suggests that the watershed response is not only affected by rainfall, but also by other parameters that play important roles.

\section{REFERENCES}

Adam, R., Western, A.W., Seed, A.W., 2012. An Analysis of the Impact of the Spatial Variability in Rainfall on Runoff and Sediment Predictions from a Distributed Model. Hydrological Processes, Volume 26(1), pp. 3263-3280

Anquetin, S., Braud, I., Vannier, O., Viallet, P., Boudevillain, B., Creutin, J.-D., Manus, C., 2010. Sensitivity of the Hydrological Response to the Variability of Rainfall Fields and Soils for the Gard 2002 Flash-flood Event. Journal of Hydrology, Volume 394(1-2), pp. 134-147

Borga, M., Vizzaccaro, A., 1997. On the Interpolation of Hydrologic Variables: Formal Equivalence of Multiquadratic Surface Fitting and Kriging. Journal of Hydrology, Volume 195(1-4), pp. 160-171

Caracciolo, D., Arnone, E., Noto, L.V. 2014. Influence of Spatial Precipitation Sampling on Hydrological Response at the Catchment Scale. Journal of Hydrologic Engineering, Volume 19(3), pp. 544-553

Delrieu, G., Nicol, J., Yates, E., Kirstetter, P.-E., Creutin, J.-D., Anquetin, S., Obled, C., Saulnier, G.-M., 2005. The Catastrophic Flash-flood Event of 8-9 September 2002 in the Gard Region, France: A First Case Study for the Cévennes-Vivarais Mediterranean Hydrometeorological Observatory. Journal of Hydrometeorology, Volume 6(1), pp. 34-52

Douinot, A., Roux, H., Garambois, P.-A., Larnier, K., Labat, D., Dartus, D., 2016. Accounting for Rainfall Systematic Spatial Variability in Flash Flood Forecasting. Journal of Hydrology, Volume 541(A), pp. 359-370

Emmanuel, I., Andrieu, H., Lebois, E., Flahaut, B., 2012. Temporal and Spatial Variability of Rainfall at the 1 Urban Hydrological Scale. Journal of Hydrology, Volume 430(4), pp. 162172

Emmanuel, I., Andrieu, H., Lebois, E., Janey, N., Payrastre, O., 2015. Influence of Rainfall Spatial Variability on Rainfall-runoff Modelling: Benefit of a Simulation Approach? Journal of Hydrology, Volume 531(2), pp. 337-348

Gaume, E., Bain, V., Bernardara, P., Newinger, O., Barbuc, M., Bateman, A., Blaskovicova, L., Blosch, G., Borga, M., Dumitrescu, A., Daliakopoulos, I., Garcia, J., Irimescu, A., Kohnova, S., Koutroulis, A., Marchi, L., Matreata, S., Media, V., Preciso, E., Sempere-orres, D., Stancalie, G., Szolgay, J., Tsanis, I., Velasco, D., Viglione, A., 2009. A Compilation of Data on European Flash Floods. Journal of Hydrology, Volume 367(1-2), pp. 70-78 
Leblois, E., Creutin, J.-D., 2013. Space-time Simulation of Intermittent Rainfall with Prescribed Advection Field: Adaptation of the Turning Band Method. Volume 49, pp. 3375-3387

Naulin, J.-P., Payrastre, O., Gaume, E., 2013. Spatially Distributed Flood Forecasting in Flash Flood Prone Areas: Application to Road Network Supervision in Southern France. Journal of Hydrology, Volume 486, pp. 88-99

Nicotina, L., Celegon, E., Alessi, Rinaldo, A., Marani, M., 2008. On the Impact of Rainfall Patterns on the Hydrologic Response. Water Resource Research, Volume 44(12), pp. 1-14

Rodriguez, F., Andrieu, H., Morena, F., 2008. A Distributed Hydrological Model for Urbanized Area - Model Development and Application to Case Studies. Journal of Hydrology, Volume 351(3-4), pp. 268-287

Rodriguez, F., Andrieu, H., Morena, F., 2008. A Distributed Hydrological Model for Urbanized Area - Model Development and Application to Case Studies. Journal of Hydrology, Volume 351(3-4), pp. 268-287

Tetzlaff, D., Uhlenbrook, S., 2005. Significance of Spatial Variability in Precipitation for Process-Oriented Modelling: Results from Two Nested Catchments using Radar and Ground Station Data. Hydrology and Earth System Sciences, Volume 9, pp. 29-41

Versini, P.-A., Gaume, E., Andrieu, H., 2010a. Application of Distributed Hydrological Model to Design of Road Inundation Warning System for Flash Flood Prone Area. Natural Hazards and Earth System Sciences, Volume 10, pp. 805-817

Wheater, H.S., Isham, V.S., Cox, D.R., Chandler, R.E., Kakou, A., Northrop, P.J., RodriguezIturbe, I., 2000. Spatial Temporal Rainfall Fields: Modelling and Statistical Aspect. Hydrology and Earth System Sciences, Volume 4(4), pp. 581-601

Wood, E.F., Sivapalan, M., Beven, K., Band, L., 1988. Effects of Spatial Variability and Scale with Implications to Hydrologic Modeling. Journal of Hydrology, Volume 102(1-4), pp. $29-47$

Zhao, F., Zhang, L., Chiew, F., Vaze, J., Cheng, L. 2013. The Effect of Spatial Rainfall Variability on Water Balance Modelling for South-Eastern Australian catchments. Journal of Hydrology, Volume 493, pp. 16-29

Zoccatelli, D., Borga, M., Wanon, F., Antonescu, 2010. Which Rainfall Spatial Information for Flash Flood Response Modelling? A Numerical Investigation based on Data from the Carthian Range, Romania. Journal of Hydrology, Volume 394, pp. 148-161 